\title{
Pulmonary Manifestations in Paediatric Rheumatic Diseases (PRDs): Experience in Tertiary Care Hospital
}

\author{
MOHAMMAD IMNUL ISLAM ${ }^{1}$, KALAYAN BENJAMIN GOMES ${ }^{2}$, MUJAMMEL HAQUE ${ }^{3}$, MOHAMMED \\ MAHBUBUL ISLAM ${ }^{4}$, MANIK KUMAR TALUKDER ${ }^{4}$, SHAHANA RAHMAN ${ }^{5}$
}

\begin{abstract}
Background: There are several forms of pulmonary manifestations in Paediatric Rheumatic Diseases (PRDs), not only by the disease itself, but also by infections and toxicity of medications used for treatment.

Objectives: To evaluate the pulmonary manifestations and to identify their pattern in PRDs including Systemic Lupus Erythematosus (SLE), Juvenile Idiopathic Arthritis (JIA), Systemic Sclerosis (SSc), Juvenile Dermatomyositis (JDM) and Polyarteritis Nodosa (PAN) patients.

Methods: It was a cross-sectional analytical study. PRDs with pulmonary problems who attended the Paediatric Rheumatololgy follow up clinic of BSMMU from January 2010 to December 2014 were enrolled in this study. All patients having PRDS with pulmonary symptoms were investigated by chest $x$-ray. High regulation CT scan of Chest (HRCT) and pulmonary function tests (PFTs) were done in some of the feasible cases.
\end{abstract}

Results: Total 20 cases were identified as paediatric rheumatic diseases with pulmonary manifestations. Out of them 8 patients were diagnosed as SLE, 6 patients as SSc, 4 patients as JIA, and 2 patients as JDM and PAN respectively. Mean age of the patients were 8.5 years. Fever (86.8\%), prolonged cough (65\%), dyspnoea (29\%) and chest pain (3\%) were the common pulmonary features. Pneumonitis (35\%), pleural effusion (29.3\%), consolidation (23.5\%) were important radiological findings. Chest CT were done in 5 patients and features of brochiectasis (75\%), thickening (25\%), pleural effusion (50\%) and pneumonitis (50\%) were found. The higher rate of pulmonary involvement was found in Ssc (100\%). Spirometric analysis were done in only 7 patients and found restrictive pattern of defect and most of them were SSC.

Conclusion: Pulmonary manifestations in PRDs were not uncommon. SLE, JIA and SSc were the predominant PRDs who had pulmonary manifestations obsevered in this study. So timely intervention of this issue could minimize morbidity and mortality of these diseases in the long run.

Key words: Pulmonary Manifestations, Paediatric Rheumatic Diseases, SLE, JIA, Systemic sclerosis.

1. Associate Professor, Department of Paediatrics, Bangabandhu Sheikh Mujib Medical University, Dhaka

2. MD Phase B Resident, Department of Paediatrics, Bangabandhu Sheikh Mujib Medical University, Dhaka

3. Paediatrician, Square Hospital, Dhaka

4. Assistant Professor, Department of Paediatrics, Bangabandhu Sheikh Mujib Medical University, Dhaka

5. Professor of Paediatrics \& Chairman, Dept. of Paediatrics, Bangabandhu Sheikh Mujib Medical University, Dhaka

Correspondence: Dr. Mohammad Imnul Islam, Associate Professor, Department of Paediatrics, Bangabandhu Sheikh Mujib Medical University, Dhaka, Bangladesh. M- 01711393049. Email : imon27@gmail.com.

Received: 26 February 2017
Introduction:

Paediatric Rheumatic Diseases (PRDs) are multisystem, inflammatory, autoimmune diseases. Symptoms in children may be subtle or absent and often develop over time. ${ }^{1}$ Lungs are among the most affected organs in these disorders. Several forms of pulmonary complications may occur in rheumatic disorders: by the disease itself, and also by infection and toxicity of medications used for the treatment Thus, there are no specific patterns of pulmonary involvement in these diseases. ${ }^{2}$ Clinical presentation, 
prognosis and response to therapy depend on the histological pattern, as well as the type of disease. ${ }^{3}$ Pulmonary involvement is a major cause of morbidity and mortality in paediatric rheumatic diseases in children; however recognizing pulmonary complications is often difficult and requires anticipation and a high index of suspicion. ${ }^{4}$

Importance of PRDs are gradually increasing globally. But it had been difficult to establish the extent of PRDs in defined populations. ${ }^{5}$ Prevalence of $\mathrm{JIA}$, which is the commonest rheumatological problem in children varies from 19.8 to 400 per 100000 children in different areas of the world. ${ }^{6}$ Prevalence of paediatric SLE ranges from 1.89 to 25.7 per 100000 which is the second most common PRDs. ${ }^{7}$ Rheumatologic diseases that can present with pulmonary manifestations in children are: Juvenile Idiopathic Arthritis (JIA), Systemic Lupus Erythematosus (SLE), Juvenile Systemic Sclerosis (SSc), Juvenile Dermatomyositis (JDM) and Polyarteritis Nodosa (PAN). ${ }^{8}$

The aim of this study was to describe the pulmonary manifestations related to paediatric rheumatic diseases including JIA, SLE, SSc, PAN, JDM and to correlate these findings with clinical manifestations, imaging and pulmonary function tests.

\section{Methods:}

A cross-sectional analytical study involving the patients having PRDs with pulmonary symptoms was performed to evaluate the types of pulmonary manifestations among the cases. Paediatric rheumatological patients with pulmonary symptoms attending the pediatric rheumatology outpatient clinic and in patient department of paediatrics, Bangabandhu Sheikh Mujib Medical University, Dhaka, Bangladesh from January 2010 to December, 2015 were enrolled in this study. Patients fulfilling the ILAR classification criteria for $\mathrm{JIA},{ }^{9}$ revised ACR (American College of Rheumatology) classification criteria 1997 for SLE, ${ }^{10}$ Bohan A, Peter JB classification criteria for JDM ${ }^{11}$, preliminary criteria for the classification of Systemic Sclerosis (SSc) ${ }^{12}$ and EULAR /PReS criteria for PAN ${ }^{13}$ were considered in this study. All the patients diagnosed as SLE, JIA, SSc, JDM and PAN who had pulmonary symptoms were investigated by chest $x$ ray. Chest HRCT and pulmonary function tests (PFTs) were done in feasible patients.

Spirometry was done using a computerised Cardiotouch 3000 spirometer version 4.5 pulmonary function unit to assess pulmonary function. Spirometric variables measured included forced vital capacity $(F V C)$, forced expired volume in one second $\left(F E_{1}\right)$ and FEV1/FVC ratio. Pulmonary dysfunction was defined as either restrictive ( $\mathrm{FEV}_{1} / \mathrm{FVC}$ e" $70 \%$ and $\mathrm{FEV}_{1}$ was normal or $<80 \%$ of predicted value) and obstructive defect $\left(\mathrm{FEV}_{1} / \mathrm{FVC}<70 \%\right.$ and $\mathrm{FEV}_{1}$ was $<80 \%$ of predicted value). ${ }^{14}$

All data were collected in a predesigned questionnaire and data were analyzed manually. Results from the pulmonary function tests were expressed as a percentage of reference values.

\section{Result}

Total 20 patients were enrolled in this study who were identified as pulmonary manifestations with PRDs.. Among them 8 patients had SLE, 6 had SSc, 4 had JIA, 1 had JDM, and 1 had PAN. According to subtypes of JIA 2 patients were diagnosed as polyarticular JIA, 1 was systemic JIA and one was enthesitis related arthritis. Male female ratio was equal. Mean age at diagnosis was 10.3 years (range 1.5-14). (Table I).

Table-I

Characteristics of the Study Population ( $N=20)$

\begin{tabular}{lc}
\hline Diagnosis & Frequency/Percentage \\
\hline JIA (SOJIA) & 1 \\
JIA (Poly) & 2 \\
JIA (ERA) & 1 \\
SLE & 8 \\
JDM & 1 \\
SSc & 6 \\
PAN & 1 \\
Female & $50 \%$ \\
Male & $50 \%$ \\
Mean age at diagnosis (year) & 10.3 (Range 1.5-14) \\
Duration of disease (months) & 9.5 (Range- 1 - 18) \\
\hline
\end{tabular}

Prolong cough, dyspnoea and chest pain were the main clinical presentations of these patients. Prolonged cough were predominately found in the JIA patients (100\%) followed by SLE patients $(62.5 \%)$ and SSc patients (33.4\%). Dyspnoea were also found in JIA, SLE and Ssc patients. On the other hand, chest pain was found only in the SLE patients. 
Table II

Clinical Presentation of the Patients $(N=20)$

\begin{tabular}{lccc}
\hline Presentations & $\mathrm{JIA}(\mathrm{n}=4)$ & $\mathrm{SLE}(\mathrm{n}=8)$ & $\mathrm{Ssc}(\mathrm{n}=6)$ \\
\hline Prolonged cough & $100 \%$ & $62.5 \%$ & $33.4 \%$ \\
Dyspnoea & $50 \%$ & $25 \%$ & $16.7 \%$ \\
Chest pain & 0 & $50 \%$ & 0 \\
\hline
\end{tabular}

Abnormal findings in chest X-ray showed pneumonitis, opacity, pleural effusion. In total $35 \%$ patient had features of pneumonitis, $30 \%$ had opacity, $25 \%$ had unilateral or bilateral pleural effusion. A few patients in this study also had consolidation and pleural thickening in their chest $x$-ray. Radiological abnormalities were found predominantly in SLE patients followed by JIA patients. (Table III)

In chest HRCT, $60 \%$ patients had abnormal findings, which included ground glass appearance, pleural thickening, fibrosis, pneumonitis and pleural effusion. In most of the SSc patients showed HRCT chest findings followed by JIA and SLE patients. (Table-IV) Overall $35 \%$ patient had abnormal spirometric values in this study. Restrictive pattern of defect was found in SSc, JDM and PAN patients. (Table -V)

Table-III

Abnormalities in Chest Xray $(N=20)$

\begin{tabular}{lcccccc}
\hline Findings & $\begin{array}{c}\text { SLE } \\
(\mathrm{n}=8)\end{array}$ & $\begin{array}{c}\text { JIA } \\
(\mathrm{n}=4)\end{array}$ & $\begin{array}{c}\text { PAN } \\
(\mathrm{n}=1)\end{array}$ & $\begin{array}{c}\text { JDM } \\
(\mathrm{n}=1)\end{array}$ & $\begin{array}{c}\text { Ssc } \\
(\mathrm{n}=6)\end{array}$ & Total \\
\hline Unilateral pleural effusion & $3(37.5 \%)$ & 0 & 0 & 0 & 0 & $3(15 \%)$ \\
Bilateral pleural effusion & $2(25 \%)$ & 0 & 0 & 0 & 0 & $2(10 \%)$ \\
Opacity & $2(25 \%)$ & $2(50 \%)$ & 0 & 0 & $2(33.3 \%)$ & $6(30 \%)$ \\
Pleural thickening & $1(12.5 \%)$ & 0 & 0 & 0 & 0 & $1(5 \%)$ \\
Consolidation & $1(12.5 \%)$ & $1(25 \%)$ & 0 & 0 & 0 & $2(10 \%)$ \\
Pneumonitis & $3(37.5 \%)$ & $3(75 \%)$ & 0 & 0 & $1(16.7 \%)$ & $7(35 \%)$ \\
\hline
\end{tabular}

Table IV

Abnormal Chest HRCT $(N=12)$

\begin{tabular}{lcccccc}
\hline Findings & SLE & JIA & PAN & JDM & Ssc & Total \\
\hline Unilateral pleural effusion & 0 & 0 & 0 & 0 & 0 & 0 \\
Bilateral pleural effusion & $1(12.5 \%)$ & 0 & 0 & 0 & 0 & $1(5 \%)$ \\
Ground glass appearance & 0 & 0 & 0 & 0 & $3(50 \%)$ & $3(15 \%)$ \\
Pleural thickening & $1(12.5 \%)$ & $1(25 \%)$ & 0 & 0 & $1(16.7 \%)$ & $3(15 \%)$ \\
Consolidation & 0 & $1(25 \%)$ & 0 & 0 & 0 & $1(5 \%)$ \\
Pneumonitis & 0 & $2(50 \%)$ & 0 & 0 & $1(16.7 \%)$ & $3(15 \%)$ \\
Fibrosis & 0 & 0 & 0 & 0 & $1(16.7 \%)$ & $1(5 \%)$ \\
\hline
\end{tabular}

Table V

Abnormalities in Spirometry $(N=7)$

\begin{tabular}{lcccccc}
\hline Findings & SLE & JIA & PAN & JDM & SSc & Total \\
\hline Obstructive VD n (\%) & 0 & 0 & 0 & 0 & 0 & 0 \\
Restrictive VD n (\%) & 0 & 0 & 1 & 1 & $5(83.4 \%)$ & $7(35 \%)$ \\
\hline
\end{tabular}




\section{Discussion:}

In this study we observed pulmonary manifestations in 20 patients with Peadiatric Rheumatic Diseases. Among them paediatric SLE was the highest in number followed by SSc, JIA, JDM and PAN patients. Quezada et al in their series found 14 patients with pulmonary manifestations. JIA was the highest followed by SLE and JDM found in their study. Another Brazilian study found 34 patients which included SLE, JIA, Ssc, JDM and Mixed connective tissue disease (MCTD). ${ }^{2}$ Different types of Paediatric rheumatic diseases presented almost similarly in all the above mentioned studies including our study.

In this study mean age at diagnosis was 10.3 years which may similar to Grein et al ${ }^{2}$ study where mean age was 10.9 years. Mean duration of disease was 9.5 months (range 1-18 months) in this study which was $4 \pm 2.8$ years in Quezada et al ${ }^{8}$ study. In this study, cases reported early comparison to other study. Female gender prevail in almost all rheumatic diseases but ratio of male and female patients in this study were equal. This was probably due to male sibs getting preference for seeking medical care in our country.

Radiological and spirometric abnormalities may be present even before clinical symptoms appear ${ }^{4}$. Therefore, the systematic investigation of patients with diseases known to cause lung damage should be meticulous. In this study, JDM and PAN patient had no clinical symptoms but there were abnormalities in spirometry. The most sensitive and specific method for detection of pulmonary involvement is the chest $\mathrm{HRCT}$, which is able to show abnormalities even when CXR and PFTs are normal. ${ }^{15,} 16$

In SLE, pulmonary manifestations may arise during onset of the disease or during its course. ${ }^{17}$ Pulmonary manifestations of childhood SLE are similar to those in adult SLE. Pulmonary involvement in childhood SLE is common, occurring in $25 \%$ to $75 \%$ of cases, ${ }^{5}$ and includes pleural effusion, alveolitis, pneumonia, pulmonary vasculitis, hemorrhage and pulmonary arterial hypertension. ${ }^{6,7}$ Both in adults and in children, the most common manifestation is pleurisy, accompanied in most cases by unilateral or bilateral pleural effusion, and this finding occurs in about 50\% to $80 \%$ of adults and 5 to $67 \%$ of children. ${ }^{12}$ In this study, Pnemonitis and pleural effusion were found in $60 \%$ of patients in their x-ray. Gerin et $\mathrm{al}^{2}$ and Quezada et al ${ }^{8}$ also found similar picture in their study. They also found pulmonary oedema, hemorrhage and opacities in the chest $x$-ray in their series. Pulmonary function tests (PFTs) were normal in the present study as because pulmonary manifestation were less in these patients. But Lilleby et al found moderately impaired PFTs in their study. ${ }^{14}$

Pulmonary involvement is one of the major causes of death in SSc, and $18 \%$ to $42 \%$ of patients with SSc have been reported to have respiratory problems including dyspnea, abnormal chest radiograph findings and reduced forced vital capacity during the overall course of the disease. ${ }^{1}$ In Scleroderma pulmonary involvement is more common in the systemic form of scleroderma, but may also occur in localized (linear) disease. Pulmonary fibrosis is observed in up to $90 \%$ of the chest HRCTs in adults, and is one of the common causes of restrictive lung disease. ${ }^{15}$ This present study showed that $100 \%$ of the SSc patients had alterations in the chest HRCT and $83 \%$ had abnormalities in spirometry. This finding were similar to the Shahane A study. ${ }^{18}$ It is to be noted that chest $x$-ray is not a good tool to evaluate these patients, in spite of that three patients in this study showed opacities and pneumonitis in their chest x-rays. Gerin et $\mathrm{al}^{2}$ also found similar results in their study.

Systemic JIA is the subtype of JIA most frequently associated with airway manifestations, which occur in up to two thirds of cases. ${ }^{19}$ Athreya and colleagues noted interstitial lung disease (ILD) in 8 of 191 children with JIA, all of whom had systemic onset. ${ }^{20}$ In this study $100 \%$ JIA patients had complaints of prolonged cough, all patients had abnormal CXR and HRCT findings mostly pneumonitis probably due to immunosuppressed condition both due to drugs and disease process as well. ${ }^{19}$ Quezada et $\mathrm{al}^{8}$ found asymptomatic sub-pleural nodule in the Chest $\mathrm{x}$-ray of the JIA patients.

According to the literature, pulmonary involvement in JDM is rare, although it can occur in $30 \%$ to $50 \%$ of adults with DM. ${ }^{4}$ In this study, there was only one JDM patient who had abnormal pulmonary function test. Spirometric analysis revealed restrictive lung disease in this patient. In generally, JDM patients have less restrictive pulmonary function than those with adult. Mathiesen et al reported that $82 \%$ of patients with JDM had normal lung function after long term follow up. ${ }^{21}$ Same restrictive defect was also found in only one PAN patients in this series.

This present study had some limitations including small sample size. Only symptomatic patients were 
submitted to tests, and only few patients performed pulmonary function tests where feasible.

\section{Conclusions:}

Pulmonary involvement often occurs in PRDs. There are varieties of manifestations in all these disorders and there are no pathognomic signs of pulmonary involvement in each disease. Health professionals should be aware of the possibility of pulmonary involvement in PRDs. It is essential to do routine checks of pulmonary function in all patients with rheumatic diseases even in the absence of respiratory symptoms in order to detect it early and initiate adequate treatment meticulously.

\section{References:}

1. Feng B W, Nong B R, Huang $Y$ F, Chiou $Y H$. Pulmonary involvement in childhood Rheumatic Disease. J Pediatr Resp Dis. 2015;11:5-11.

2. Grein IHR, Pejajo CF,Meneghati TC, Junior LLJ, Banderia M. Pulmonary menifestations of rheumatologic diseases in pediatric. Rheumatology (Sunnyvale). 2014;4:2. http:// dx.doi.org/10.4172/2161-1149.1000136

3. Crestani $B$. The respiratory system in connective tissue disorders. Allergy 2005;60:715-342.

4. Rabinovich CE. Pulmonary complications of childhood rheumatic diseases. Paediatr Respir Rev. 2012;13:29-36.

5. Petty R E. Paediatric Rheumatology: The study of Rheumatic Diseases in childhood and adolescence. In: Petty R E, Laxer R M, Lindsley C B, Wedderburn LR editors. Textbook of paediatric rheumatology. 7th edn. Philadelphia: Elesvier; 2016. p. 1-3.

6. Manners PJ, Bower C. Worldwide prevalence of Juvenile Arthritis-Why does it vary so much? J Rheumatol. 2002;29:1520-30.

7. Pineles D, Valente A, Warren B, Peterson MGE, Lehman TJA, Moorthy LN. Worldwide incidence and prevalence of pediatric onset systemic lupus erythematosus. Lupus. 2011;0:1-6.

8. Quezada A, Ramos S, Garcia M, Norambuena $X$, Pavon D. Lung involvement in rheumatologic diseases in children. Allergol Immunopathol (Madr). 2012;40:88-91.

9. Petty RE, Southwood TR, Manners P, Baum J, Glass DN, Goldenberg J, et al. International League of Associations for rheumatology classification of juvenile idiopathic arthritis: $2^{\text {nd }}$ revision, Edmonton, 2001. J Rheumatol. 2004;31:390-2.

10. Hochberg MC. Updating the American College of Rheumatology revised criteria for the classification of systemic lupus erythematosus. Arthritis Rheum. 1997;40:1725.

11. Rider GL, Lindsley CB, Miller FW . Juvenile Dermatomyositis. In: Petty R E, Laxer R M, Lindsley C B, Wedderburn LR editors. Textbook of paediatric rheumatology, 7th edition. Elsevier; Philladelphia: 2016.p.351-383.

12. Zullian F. Systemic sclerodermas. In: Petty $R$ E, Laxer R M, Lindsley C B, Wedderburn LR editors. Textbook of paediatric rheumatology, 7 th edition. Elsevier; Philladelphia: 2016. p. 384-405.

13. S Ozen, N Ruperto, M J Dillon, A Bagga, K Barron, JC davin, et al. EULAR/PReS endorsed consensus criteria* for the classification of childhood vasculitides. Ann Rheum Dis. 2006;65:936-41.

14. Lilley V, Alloken TM, Johnson B, Forre O. Pulmonary involvement in patients with Childhood onset Systemic Lupus Erythematosus. Clinical and Experimental Rheumatology. 2006;24:203-8.

15. Chapin R, Hant FN. Imaging of scleroderma. Rheum Dis Clin North Am. 2013;39:515-46.

16. García-Peña P, Boixadera H, Barber I, Toran N, Lucaya J, Enriquez G, et al. Thoracic findings of systemic diseases at high-resolution CT in children. Radiographics. 2011;31:465-82.

17. Malattia $C$, Martini A. Paediatric-onset systemic lupus erythematosus. Best Pract Res Clin Rheumatol. 2013;27:351-62.

18. Shahane A. Pulmonary hypertension in rheumatic diseases: epidemiology and pathogenesis. Rheumatol Int. 2013;33:16551667.

19. Domingues $\vee$, Rodrigues MC, Diniz CC, Almeida RG. The respiratory tract and juvenile rheumatic diseases. Rev Bras Reumatol. 2011;51:81-96.

20. Athreya $B H$, Doughty RA, Bookspan M, Schumacher HR, Sewell EM. Pulmonary manifestations of juvenile rheumatoid arthritis. A report of eight cases and review. Clin Chest Med. 1980;1:361-74.

21. Mathiesen PR, Buchvald F, Nielsen KG, Herlin $T$, Friis T, Nielsen S. Pulmonary function and autoantibodies in a long-term follow-up of juvenile dermatomyositis patients. Rheumatology (Oxford). 2014;53:644-49. 